\title{
EXTENSION OF IFC SCHEMA IN CONSTRUCTION DELAY CLAIMS
}

\author{
Akram M. Hammam ${ }^{1}$ Moheeb El-Said ${ }^{2}$ \\ ${ }^{1}$ Senior Construction Forensic Claims/ Delay Analyst and Ph.D. Candidate, Cairo University, \\ Cairo, Egypt \\ ${ }^{1}$ Structural Engineering Department, Construction Engineering and Management, Faculty of \\ Engineering, Cairo University, Cairo, Egypt,
}

\begin{abstract}
Despite the widespread implementation of Building Information Modelling (BIM) in Construction and Facilities Management, limited researches are conducted on forensic delay claims. As witnessed from several construction disputes and court cases, forensic delay claims are known to be the most complex types of claims, in which Claimants incur significant losses due to their failure to substantiate. Despite the availability of modern document control system, forensic delay claims require extensive research to assimilate event related contemporaneous project records within a limited time. This paper addresses the research gap of the application of BIM technology in the assessment of forensic claims. It proposes a new mechanism of extending the non-proprietary Industry Foundation (IFC) Schema by dynamic property sets to integrate BIM objects with claim related attributes such as delay events and float paths and their respective project documents. The proposed methodology enhances the overall efficiency of the forensic claim process enabling the retrieval of all spatial related project documents pertaining to a specified delay event. This allows the performance of whatif scenarios for the optimum selection and substantiation of a delay claim.
\end{abstract}

\section{KEYWORDS: Delay Analysis, IFC, BIM, Claims}

\section{INTRODUCTION}

Forensic Delay claims which are characterized by their complexity, protracted and costly preparation when compared to other types of Claims (Bramble and Callahan 2010). They constitute a large portion of construction claims and are considered the most common form of construction disputes (Carnell 2005). Review of several court cases revealed that claimants incur substantial losses due to failure to submit a credible claim, despite having grounds for entitlement (Pickavance 2005). This failure is attributed mainly to a Claimant's failure to evidently identify the cause and effect of a delay claim by overlooking crucial information. Even with the available Document Management Systems (DMS), Claimants experience difficulty in assimilating and correlating vast amount of project documents from different sources to substantiate delay claims (Carmichael and Murray 2006).

In light of the above, it can be concluded that the delay claim process could benefit from the introduction of new methodologies and technologies currently implemented in the Construction Industry. Of those new methodologies currently applied and has currently revolutionized the Construction industry is Building Information Modelling (BIM). BIM technology provides a common platform that integrates and supports project stakeholders (Owners, Designers, Contractors, and Suppliers etc.) and interoperability among different software. BIM implementation is not limited to $3 \mathrm{D}$ representation of models but has evolved to include adding other dimensions to the BIM model such as time (4D), cost (5D), Operation 
(6D) thus enhancing efficiency and productivity throughout all stages of the project. (Eastman et al. 2011).

The current implementations of BIM methodologies on forensic delay claims utilize 4D visualization in simulating and the forensic assessment of construction sequencing and methodologies of delay events. However, limited researches have been conducted on exploring potential benefits of BIM implementation (Gibbs et al. 2013). Forensic delay claims process could benefit from other BIM implementations. Further potentials of integrating the methodologies of forensic delay analysis processes with the current IFC Schema model would promote further interoperability with 4D BIM platforms. Moreover, the centralized approach of the BIM Model allows accessibility to all information pertaining to a given delay event.

This paper proposes a new methodology utilizes BIM's centralized approach by linking project documents to their respective BIM objects. This is carried out by extending the IFC (Industry Foundation Class) schema to incorporate properties pertaining to a delay event and path of activities. This methodology allows access to all project documents and information pertaining to a specified delay path enhancing the overall efficiency of the claim process and support the selection process of potential delay events.

\section{BACKGROUND \\ Delay Claims}

Establishing delay claims mainly consists of three major components, 1) Establishing the factual information and evidence that substantiate the claimant entitlement of additional time (standalone assessment) 2) Contractual evidence that support the claimant's entitlement for additional 3) apportionment of delay claim (delay analysis) form the remaining component of establishing delay claims (Fawzy and El-adaway 2013).

One of the major challenges of establishing entitlement in delay claims lies in the claimant's efficiency in extracting relevant project records in a timely and accurate manner. As observed from the ruling of numerous Court cases that the Claimants' failure to substantiate their claims was mainly attributed to their inability to provide contemporaneous records and evidence (Wharf Properties Ltd v Eric Cumine Associates 1991), (The Foundation Co of Canada Ltd v United Grain Growers Ltd 1995) and (Fru-Con Construction Corporation v The United States 1999).

Even with well-documented projects supported by modern Document Management Systems (DMS); the challenge remained in adapting those documents to produce a credible conclusion within a fixed period of time and limited budget. It is established that the costs of retrospectively proving a Claimant entitlement could be very expensive depending on the credibility of the gathered data (Pickavance 2005). Vital evidence required to substantiate a claim may take prolonged periods of time to recognize and retrieve. (Vidogah and Ndekugri 1998). Consequently, Claim Experts that 90 percent of arbitrator's time is consumed in establishing facts of a claim and if those facts are not demonstrated unambiguously the claim is anticipated to fail (Pickavance 2005).

The traditional process of substantiating forensic delay claims remains time-consuming and prone to errors (Carmichael and Murray 2006).

In delay analysis, retrieval of spatial documents such as material submittals, daily site records, shop drawings, photos that are distinct to specific building element(s) is a time-consuming and challenging task which is prone to errors, even with modern document management systems. This leads to vital documents pertaining to a specific spatial location are often overlooked, thus jeopardizing the integrity of the claim evaluation.

\section{Delay Analysis}

Identification and apportionment of delays in construction projects are determined through delay analysis methods (Lowsley and Linnett 2006); (Fawzy and El-adaway 2013). There are two major industry guidelines that are considered the reference for delay analysis, the Society of Construction Law Delay and Disruption Protocol (SCL Protocol) and the Association for the Advancement of Cost Engineering International (AACEI) in the form of its 'Recommended Practice No. 29R-03 Forensic Schedule Analysis (RP-FSA)' (AACEI Commitee 2011).

The standard processes conducted in the majority of delay analysis methodologies are initiated by establishing an Activity-Level Variance (ALV) to identify start/finish and duration 
variances in a time programme (AACEI Commitee 2011), upon which delay events are identified using either the Cause or Effect-Based approaches. The Cause-Based approach is identified vide project records (letters, material submittals, inspection requests) the impact of suspected causes of a delay on the time programme. On the opposite, the Effect-Based approach identifies the effect of the ALVs as derived from the comparison of an as-built time programme with a baseline programme and subsequently identifying the cause of the ALVs by thoroughly reviewing a set of project documents within a specified time frame (Caletka 2008).

The causation established in both approaches is dependent on the quality and reliability of documents. Hence it is vital to establish a 'document-type' list in a chronological order prior to a delay analysis review (AACEI Commitee 2011).

Another aspect to consider when identifying delays should not be limited to the delays occurring on the critical or longest path. Criticality of a programme is dynamic in which criticality of activities changes from critical to near critical in every programme update both approaches are referred to as the 'Longest Path Theory' and 'Total Float Value' (Caletka 2008). The 'Longest Path Theory' is defined as the total sum of activity durations that determine the project completion date while the 'Total Float Value' Theory is defines as any sub-critical path in a time programme that impacts the Contract completion date (which is the date set out in the Contract and does not change unless an Extension of Time is awarded).

\section{Project Records}

Despite the widespread and application of modern Document Management Systems (DMS), numerous problems encounter the classification and retrieval of project documents. Modern DMS systems facilitate access and retrieval of documents, but issues remain regarding the efficiency to cross reference and derive event-related documents which becomes timeconsuming and prone to errors (Carmichael and Murray 2006). A study proposed a new classification for documents using information breakdown structure and space breakdown structure to facilitate document control (Lee and Cha 2015). Another study used the WBS to manage information in spatial, time dimensions to control the information process (Wang et al. 2015). The author introduces a study to incorporate project documents in a Work breakdown Structure (WBS) database design using construction project schedules and a BIM model. (Park and Cai 2017)

\section{Industry Foundation Classes IFC}

Industry Foundation Classes (IFC) is a standard for data exchange developed to describe Architecture, Engineering and Construction (AEC) industry data. IFC is an open file format data model developed by BuildingSMART that is regularly upgraded (BuildingSMART 2018). BuildingSMART administers input from various construction industry specialists to enhance interoperability between different BIM platforms by regularly adding new entities in different construction fields. However, this process is a long term process which takes more than one year for proposed extensions to be incorporated.

The IFC object model schema is defined in EXPRESS specification language (ISO 10303-11) and the current widely adopted version is the IFC $2 \times 3$ which contains 653 building entities and is represented using the EXPRESS-G annotation Figure 1. The IFC model schema instances are specified in STEP physical files (ISO 10303-21) which is in ASCII characters format.

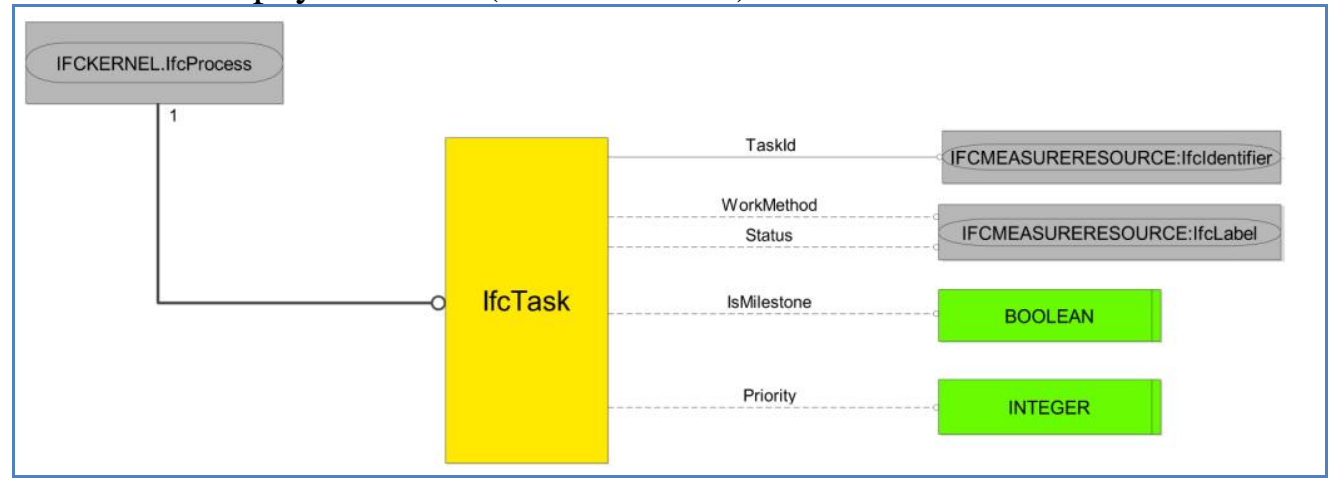

Figure 1 -Express-G annotation for IfcTask 
4D IFC

4D IFC has been further utilized in constructability and safety reviews during preconstruction such as updating and monitoring progress during construction using augmented reality and RFID (Hamledar et al. 2017). 4D IFC was integrated with a quality control and monitoring system in a proposed study (Dinga et al. 2017)).

In the IFC Schema model, time programme is represented by the ifcWorkSchedule classes, the activity IDs and descriptions are represented by the ifcTask and activity relationships ifcRelSequence. The activity tasks are linked with the associated building objects through ifcRelassignsToProcess. On the other hand, documents represented by ifcDocumentReference can be referenced with BIM objects through the entity ifcRelAssociatesDocuments Figure 2.

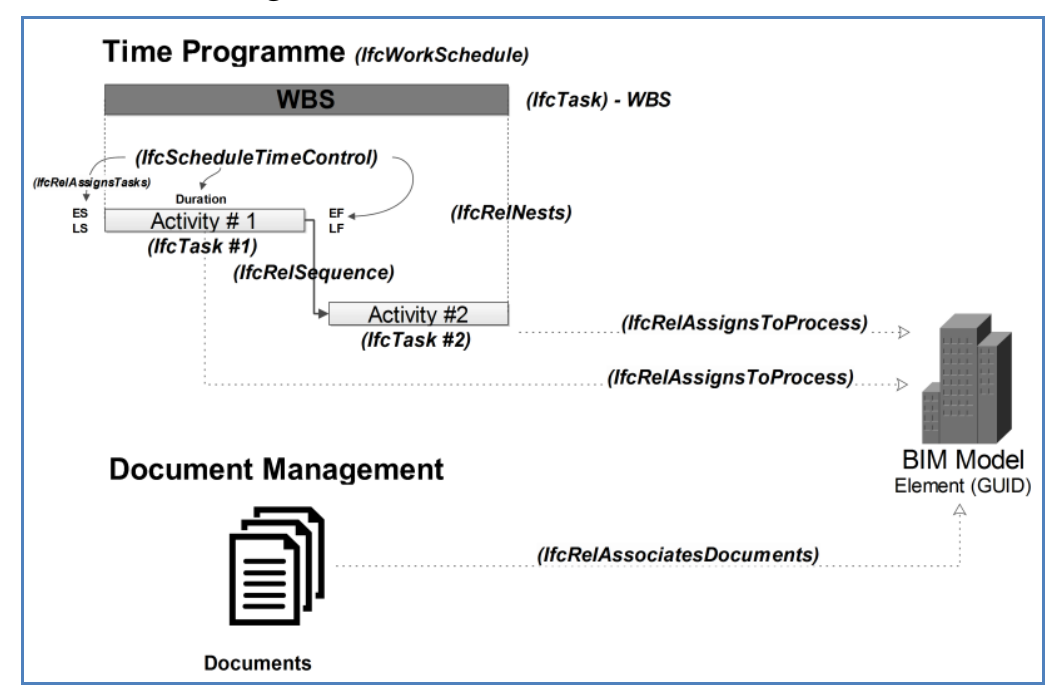

\section{Extension of IFC}

Figure 2 -IFC Schema representation of Time Programme

Despite the continuous updates of the IFC schema model, additional classes and object attributes are required to describe specific construction related areas. These additional classes are not present in the existing IFC model or the associated existing statically defined property sets. Hence, several IFC extension mechanisms are adopted to enable users to extend the IFC Schema model. One mechanism adopted which is regulated by BuildingSMART for practitioners who wish to propose new entities to the current IFC schema model. This mechanism however takes a long approval process to be introduced to the IFC schema model. For this reason, an alternative mechanism is introduced that allows extension of the IFC schema model through customized dynamic property sets. Under the IfcPropertySetDefinition entity, the IfcPropertySet is used to extend the IFC schema for a specific region, organization or project without the need to changing the available IFC schema model. IfcPropertySet is utilized to assign specific properties which are not available in the statically defined properties of the available property sets already defined in the IFC model.

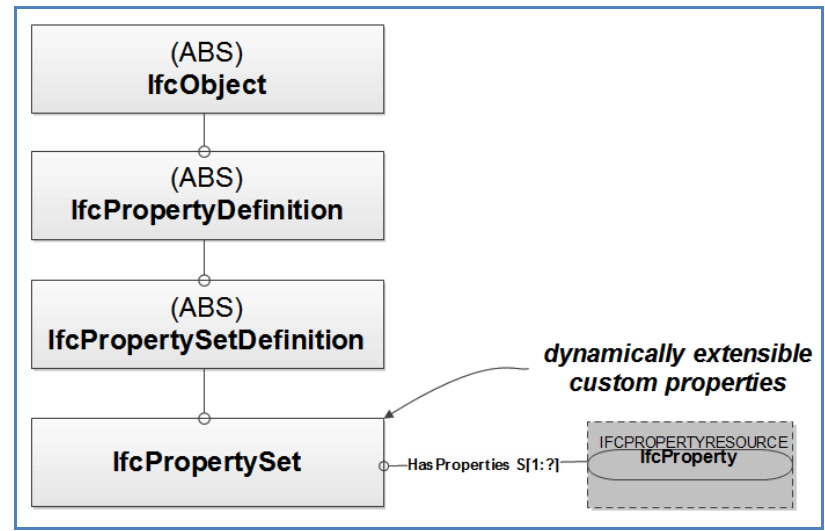

Figure 3 -IfcPropertySet for custom dynamic property set 


\section{Researches on Extending the IFC Schema}

Numerous efforts to extend the IFC Schema in various construction fields which was not possible through the current IFC Schema. A research conducted to integrate Radio Frequency Identification (RFID) for automatic data collection of building assets (Motamedi et al. 2016). Other researches were conducted to extend the IFC standard by proposing new property sets for a specific local market as the research to collect detailed construction cost estimating information specific to the Chinese construction industry to facilitate the tendering process (Zhiliang et al. 2011). Another study proposed an extension of the IfcBridgeElement by introducing information required to Support the periodic inspection tasks of a typical bridge (Tanaka et al. 2016). Research conducted to represent additional construction resource information proposing new entities to the IFC schema model ( $\mathrm{M}$ and $\mathrm{Lu} 2010)$. The IFC schema model was extended through dynamic property sets to develop a proposed Inspection Process Model (IFC-IPM) to integrate quality-related information. (Dinga et al. 2017).

Aim of study

This study proposes an IFC based methodology to enhance and facilitate the overall forensic delay claim evaluation process. The proposed methodology utilizes spatial and time data available in an IFC 4D extended model. To achieve this goal, a proposed system based on the extension of the non-proprietary Industry Foundation Class IFC (2X3) Schema was required to incorporate the explicit features of delay analysis methodologies. Despite the available 4D features available in the IFC Schema, additional features was incorporated that further describe the two approaches of criticality in delay analysis ('Total Float Value' and the 'Longest Path') theories by distinguishing the critical and near-critical path activities of a specified delay event in the 4D BIM model. In applying this IFC extension, the features associated with the Time Impact Analysis method (MIP 3.7) is fully represented in the 4D BIM model i.e. the time window under study for the delay event, the driving path of activities for the subject delay event.

On the other hand, the study proposed an algorithm to retrieve spatial documents associated with a delay event path of a specified time analysis window. This method enhances the efficiency of information retrieval when assessing a delay event and subsequently the overall performance of the claim evaluation process when compared to the traditional claim process (see figure 4).

The extended IFC schema is readable in most commercial BIM software depending on their different capabilities.

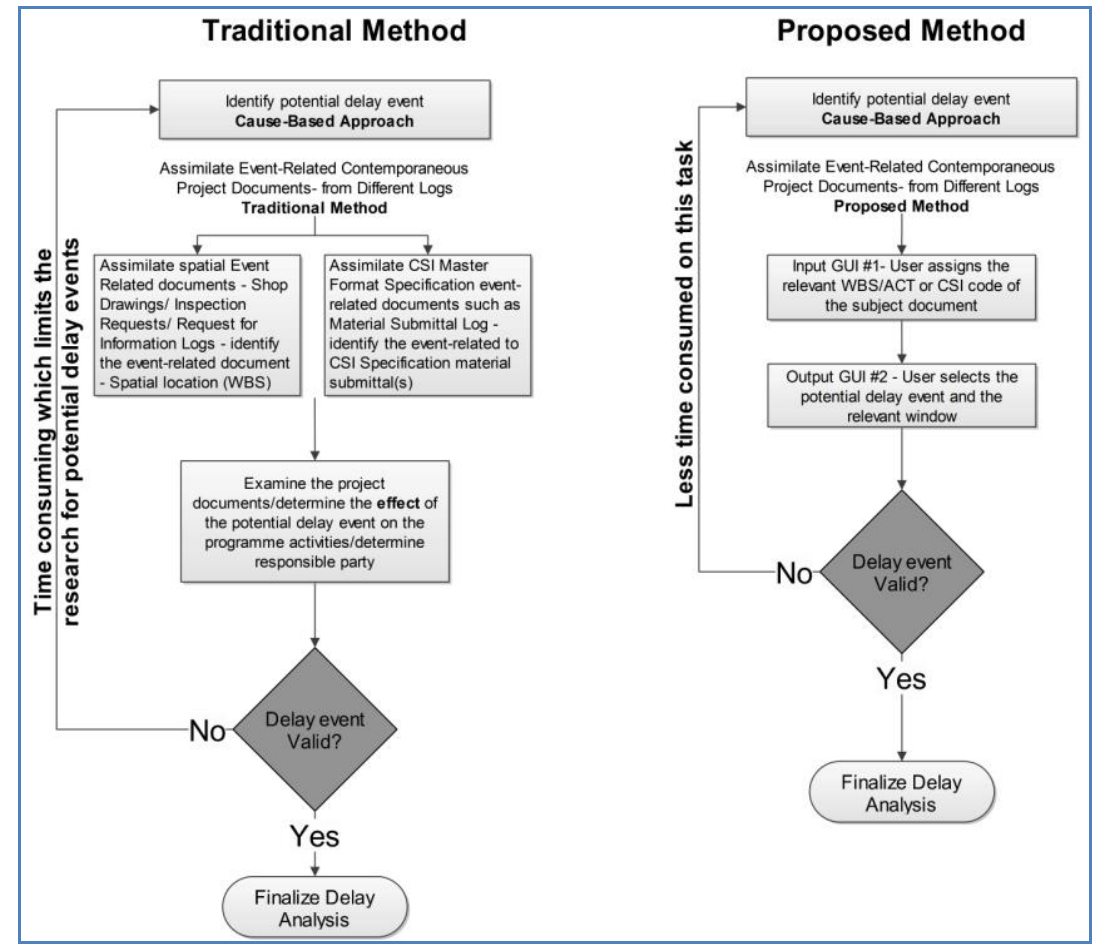

Figure 4-Comparison between the Traditional and Proposed claim evaluation process 


\section{Proposed extension of IFC Schema to support Delay Claims}

The proposed study is conducted on a warehouse project in the United Arab Emirates. The proposed project is divided into three construction zones A1, A2 and A3; it is composed of concrete foundation, structural steel frame and cladding. The following is maintained throughout the project duration, 1) a 3D BIM model is developed progressively throughout the project life cycle, 2) a baseline time programme and its monthly updates and 3) Different types of project records (material submittals, inspection requests, shop drawings etc.... In the proposed study, a sample of three potential delay events are selected within specified windows of analysis to conduct the study. A Cause-Based approach was conducted to identify the cause and effect of the delay event. An algorithm is proposed to extract event-related contemporaneous project records associated with all the BIM objects of the related delay event path as per the steps shown in the below figure.

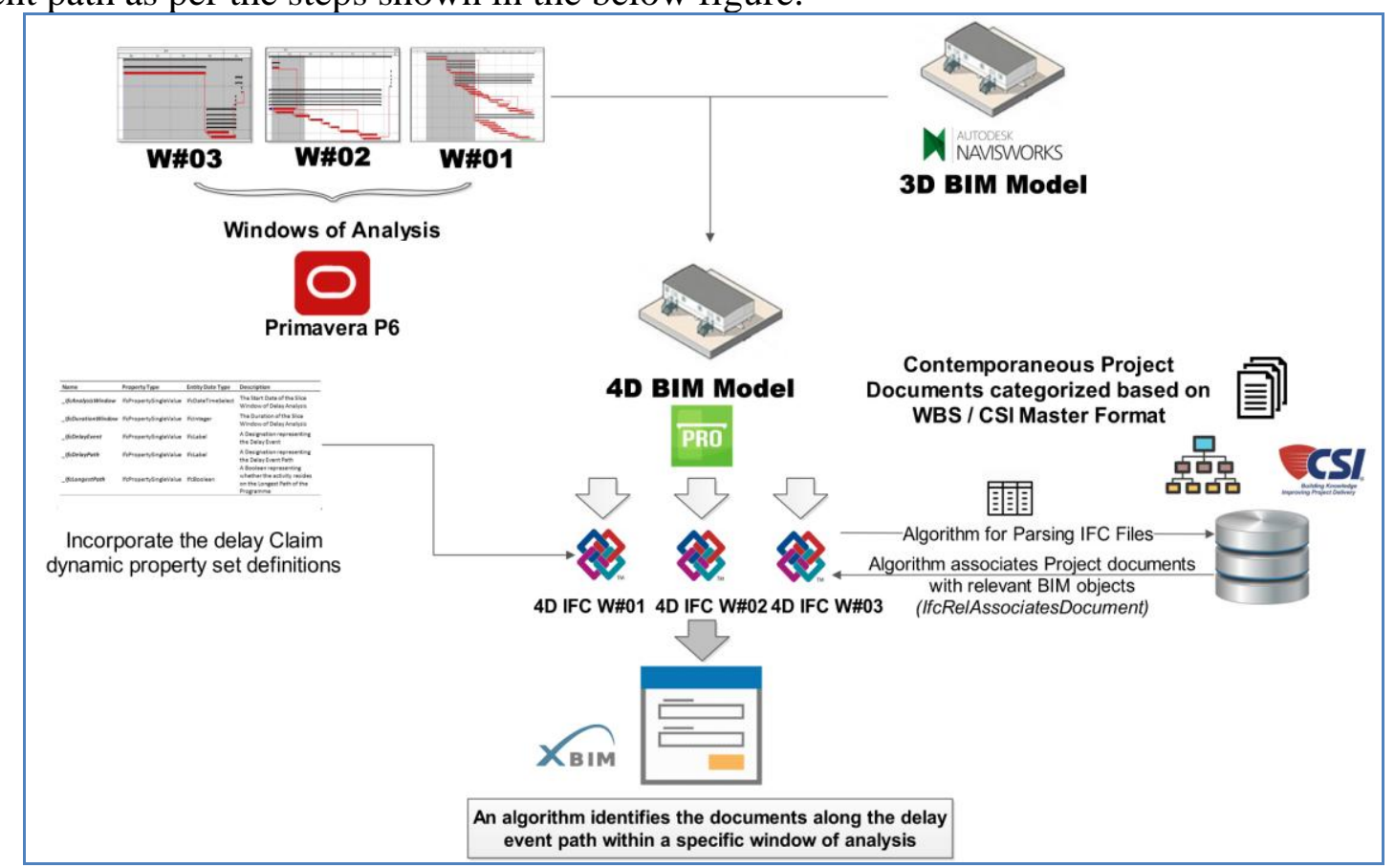

Figure 5 - Proposed IFC extension methodology

\section{Step 1 - Data Preparation}

- BIM Model/Time Programme/contemporaneous project documents

A Revit BIM model of a warehouse is created composed of concrete foundations, a steel structure and Architectural finishes and cladding. A baseline programme is prepared composed of 90 activities organized by a work breakdown structure (WBS) (4 - levels). Updates of the baseline programme are maintained throughout the project on a monthly basis. On the other hand, different types of contemporaneous project documents are maintained periodically. The cotemporaneous records are a series of documents collected at the time of the event such as material submittals, shop drawings, inspection requests etc.... The contemporaneous records are categorized in the proposed study under two categories documents; 1) Spatial related documents that are defined based on Work Breakdown Structure (WBS) which identifies the space/area the document represents such as shop drawings 'Foundation drawings for Area '1' (GL AG-AH/ 112-115)', Inspection request for concrete placement at Area '3' (GL BA-BC/105-109), etc...2) Non-spatial documents representing products and material are represented by the standardized CSI Master Format such as Reinforcing Steel (032100), Cast-in-Place Concrete (03300), etc.... 
- Identifying the delay event paths and windows

Following a comparison of several time programme updates and a series of discussions, several potential delay events were initially for further investigation as shown in the below table.

Table 1 - Potential Delay Events

\begin{tabular}{cl}
\hline No. & Delay Event (IfcDelayEvent) \\
\hline 1 & DE03 - Revised Foundation Drawings \\
2 & DE14 - Revised holding bolts for Structural Steel \\
3 & DE80 - Slab Details at Level 01 - Area 04 \\
\hline
\end{tabular}

To achieve this goal a Time Impact Analysis (TIA) as recommended by the Method Implementation Protocol (MIP) 3.7 AACE industry guidelines was conducted on four time programmes, a baseline programme $\boldsymbol{B L}$, and 3 updated baseline programmes TIA01, TIAO2 and TIA03. TIA01 and TIA02 cover an analysis window labelled_IfcAnalysisWindow w\#, $\mathrm{w \# 2}$ and $\mathrm{w \# 3}$ of the potential delay event(s) DE03, DE14 and DE80_IfcDelayEvent. Window $\boldsymbol{w} \# \mathbf{1}$ analyzes the period between commencement date and end of analysis period $\boldsymbol{w} \# \mathbf{1}$, in which delay event DE03 is analyzed after insertion after data date DD1. Window w\#2 analyzes the period between start of window $\boldsymbol{w} \# \mathbf{2}$ (end of analysis period of w\#1 DD1) and (end of analysis period of w\#2 DD2). Window w\#3 analyzes the period between start of window $\boldsymbol{w \# 3}$ (end of analysis period of w\#1 DD2) and (end of analysis period of w\#3 DD3). The pre and post insertion of the delay events are then analyzed for the three windows to identify the driving path of the delay event (_IfcDelayPath) for each window.

The step generates five time programmes Baseline BL, TIA01-W\#1 (Pre and Post Impact), TIA02 -W\#2 (Pre and Post Impact) and TIA03-W\#3.

\section{- 4D model preparation}

The programme updates BL, TIA01-W\#1(Post), TIA01-W\#2(Post) and TIA03-W\#3(Post) were introduced in the 3D BIM model using Synchro pro. The activity tasks were linked to their respective BIM objects. Each programme represents the project status (early/late/actual dates) prior and post impact of the delay event. Four IFC STEP physical files (ISO 10303-21) were generated representing the 4D BIM models of the different windows of analysis (data dates). This limits the exported IFC File to only the objects represented by the driving activities along the delay event path. This process is repeated for every analysis window covering the duration of the delay event. The below figure shows the pre and post impact of delay event 'DE03' in analysis window ' 1 '.

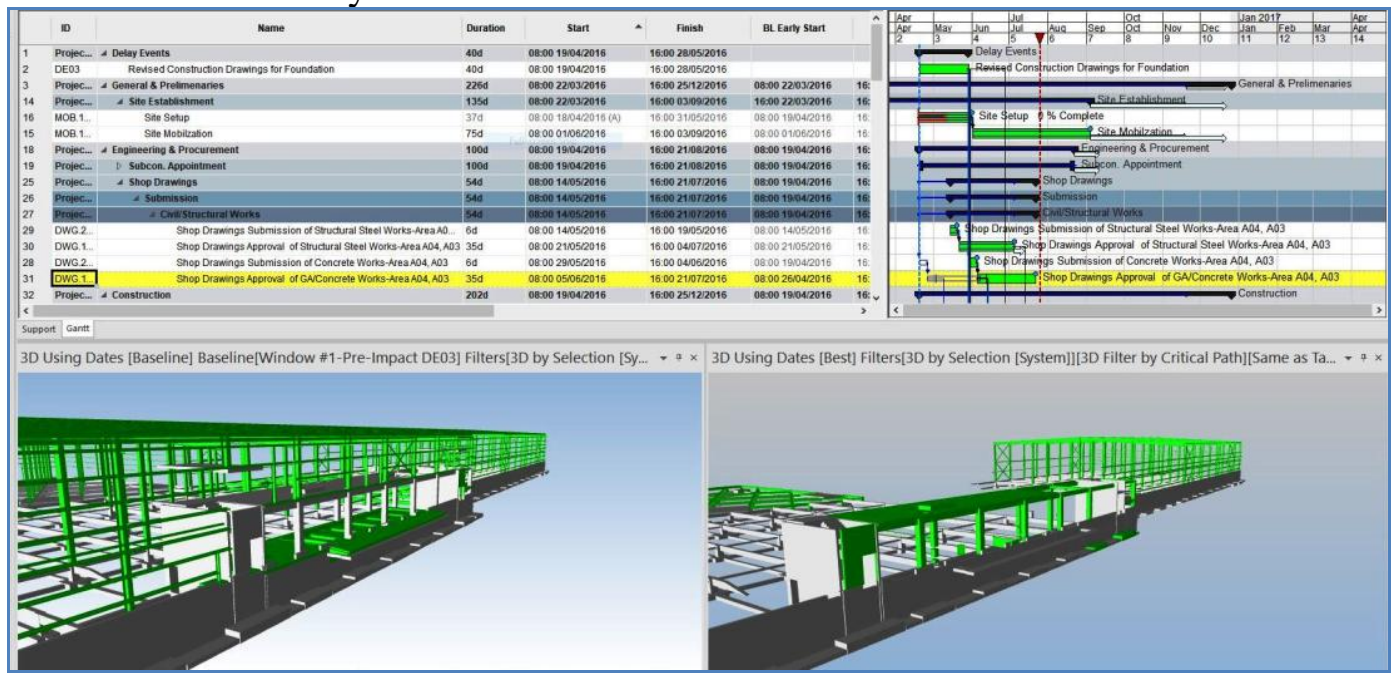

Figure 6 - Pre and post impact of delay event DE03 in analysis window\#1 


\section{Step 2 - Developing the Extended IFC model}

As stated previously, the IFC 2 X3 TC does not provide predefined classes to represent delay analysis. Hence, an extension of the IFC schema model is necessitated to further define the delay the claim process in IFC. A number of claim related dynamic property sets are introduced in the current IFC Schema 2X3 through IfcPropertySet class to support the dynamic declaration of property set definitions. The PSet_Delay_Analysis and Pset_AssignmentCode are created to define and store data defining the relative documents and the delay event path.

Table 2 - Definition of the Delay Claim Property Set

\begin{tabular}{lll}
\hline propertySetName & Application Entities & Description \\
\hline Pset_AssignmentCode & IfcBuildingElement & $\begin{array}{l}\text { Property Set to Store Information describing delay } \\
\text { path analysis and their activities }\end{array}$
\end{tabular}

Pset_DelayAnalysis IfcTask

Property Set to Store Information describing delay path analysis and their activities

The properties identifying the property set Pset_AssignmentCode includes ifcPropertySingleValue instances attached to their respective BIM objects based on two properties WBS and CSI Master Format. In other words, all BIM objects are linked to 1) a WBS reference code _IfcWBSCode as described previously in the P6 time programme, 2) a CSI Masterformat reference code_IfcCSICode to describe the object based on the Division list of the Masterformat (1995 Edition). The assignment of both properties will serve as reference code for linking the documents to the respective BIM object.

Table 3 - Definition of the Pset_AssignmentCode attributes

\begin{tabular}{llll}
\hline Attribute & Property Type & Entity Date Type & Description \\
\hline \multirow{2}{*}{ IfcWBSCode } & IfcPropertySingleValue & IfcLabel & $\begin{array}{l}\text { Work Breakdown } \\
\text { Structure Reference } \\
\text { Code }\end{array}$ \\
IffCSICode & IfcPropertySingleValue & IfcLabel & $\begin{array}{l}\text { CSI Master Format } \\
\text { Reference Code }\end{array}$ \\
\hline On the other hand the properties of the extended IFC Schema property
\end{tabular}

On the other hand, the properties of the extended IFC Schema property set Pset_Delay Analysis we as linked to the BIM objects pertaining to the delay event of each analysis window. This extension formed an integral part of the implementation of delay analysis in a 4D BIM model. The attributes included are; 1) an identification of the time frame of assessment between the data date and the subsequent window of analysis to the analysis window is identified through_IfcAnalysisWindow, 2) _IfcDurationWindow to identify the duration of each analysis window, 3) IffCDelayEvent to distinguish the activity of the delay event in the IFC schema, 4) the delay event path of activities_IfcDelayPath, 5) the longest path_IfcLongestPath of the Analysis Window that identifies the longest within the analysis window.

Table 4 - Definition of the Pset_Delay Analysis attributes

\begin{tabular}{|c|c|c|c|}
\hline Attribute & Property Type & $\begin{array}{l}\text { Entity Date } \\
\text { Type }\end{array}$ & Description \\
\hline _IfcAnalysisWindow & IfcPropertySingleValue & $\begin{array}{l}\text { IfcDateTimeSel } \\
\text { ect }\end{array}$ & $\begin{array}{l}\text { The Start Date of the Slice } \\
\text { Window of Delay Analysis }\end{array}$ \\
\hline _IfcDuration Window & IfcPropertySingleValue & IfcInteger & $\begin{array}{l}\text { The Duration of the Slice Window } \\
\text { of Delay Analysis }\end{array}$ \\
\hline _IfcDelayEvent & IfcPropertySingleValue & IfcLabel & $\begin{array}{l}\text { A Designation representing the } \\
\text { Delay Event }\end{array}$ \\
\hline _IfcDelayPath & IfcPropertySingleValue & IfcLabel & $\begin{array}{l}\text { A Designation representing the } \\
\text { Delay Event Path }\end{array}$ \\
\hline _IfcLongestPath & IfcPropertySingleValue & IfcBoolean & $\begin{array}{l}\text { A Boolean representing whether } \\
\text { the activity resides on the Longest } \\
\text { Path of the Programme }\end{array}$ \\
\hline
\end{tabular}


Those nominal attribute values are extracted from the 'activity codes' values of the Primavera P6 scheduling software and are linked to the activities in the IfcTask data table. The attribute

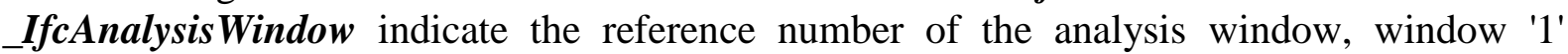
indicates window analysis between (19 April $16-22$ July 16), Window ' 2 ' indicates window analysis between (22 July 16 - 07 September 16), Window ' 3 ' indicates window analysis between (07 September 16 - 27 October 16). Attribute_IfcDurationWindow represents the duration of the analysis window_IfcAnalysisWindow, 94, 47 and 50 days for Windows 1, 2 and 3. Attribute_IfcDelayEvent represents a designation for the three delay events DE03, DE14 and DE80. Attribute_IfcDelayPath represents the designated delay event associated with the activity for example the following activities are a sample of the driving activities resulting from the impact of delay event 'DE03' on the time programmes, there are cases that an activity is common between several delay events like activity C.A03.MEP.1025, C.A03.CIV.1165, C.A03.CIV.2575 which share two or more delay events 'DE03' and 'DE14' as shown in the below table. The attribute values are generated in the P6 Primavera scheduling software and later exported to the 4D IFC files exported using Synchro pro.

Table 5 - Assignment 'Delay Path' Event to the designated activity

\begin{tabular}{lll}
\hline Activity ID & Activity Name & $\begin{array}{l}\text { Delay Path } \\
\text { (_IfcDelayPath) }\end{array}$ \\
\hline C.A03.CIV.1100 & FRP to Footing \& Tie Beam & DE03 \\
C.A03.CIV.1115 & FRP to Stub Column up to Ground Beam Bottom & DE03 \\
C.A03.CIV.1155 & Back Fill up to Ground Beam Bottom & DE03 \\
C.A03.MEP.1025 & FRP Ground Beam \& Anchor Bolt Fixing & DE03,D14 \\
C.A03.CIV.1165 & Back Fill up to Slab on Grade & DE03,D14 \\
C.A03.CIV.2575 & FRP to Walls/Columns From Ground to First & DE03,D14 \\
\hline
\end{tabular}

The final attribute_IfcLongestPath is generated from the Synchro programme assigning a Boolean attribute (Yes/No) to whether an activity is on the longest path of the window analysis programme.

Three 4D IFC files TIA01-W\#1(Post), TIA02-W\#2(Post) and TIA03-W\#3(Post) were created from Synchro pro including the extended dynamic property sets Pset_Delay Analysis and their nominal values.

\section{Step 3 - Developing the IFC Schema Model}

A database schema was developed incorporating the extended 4D IFC schema and a data table incorporating the contemporaneous project documents_ProjectRecordsProperties. IFC data tables are generated after parsing of the 4D Step-21 IFC files exported from the 4D BIM platform SynchroPro. The parsed IFC files are then mapped to their corresponding IFC Schema tables as represented in Figure 6 consisting of 1) the activity related objects represented by the connection between of the IfcTask activities with the BIM objects IfcObject and/or any building element of the model, through the relationship data table IfcRelAssignsToProcess representing the links between the activities of TIA01-W\#1(Post), TIA02-W\#2(Post) and TIA03-W\#3(Post) programmes with the BIM model 2) the delay analysis attributes of the dynamic IfcPropertySet (Pset_DelayAnalysis) are represented in the nominal values of the IfcPropertySingleValue. 


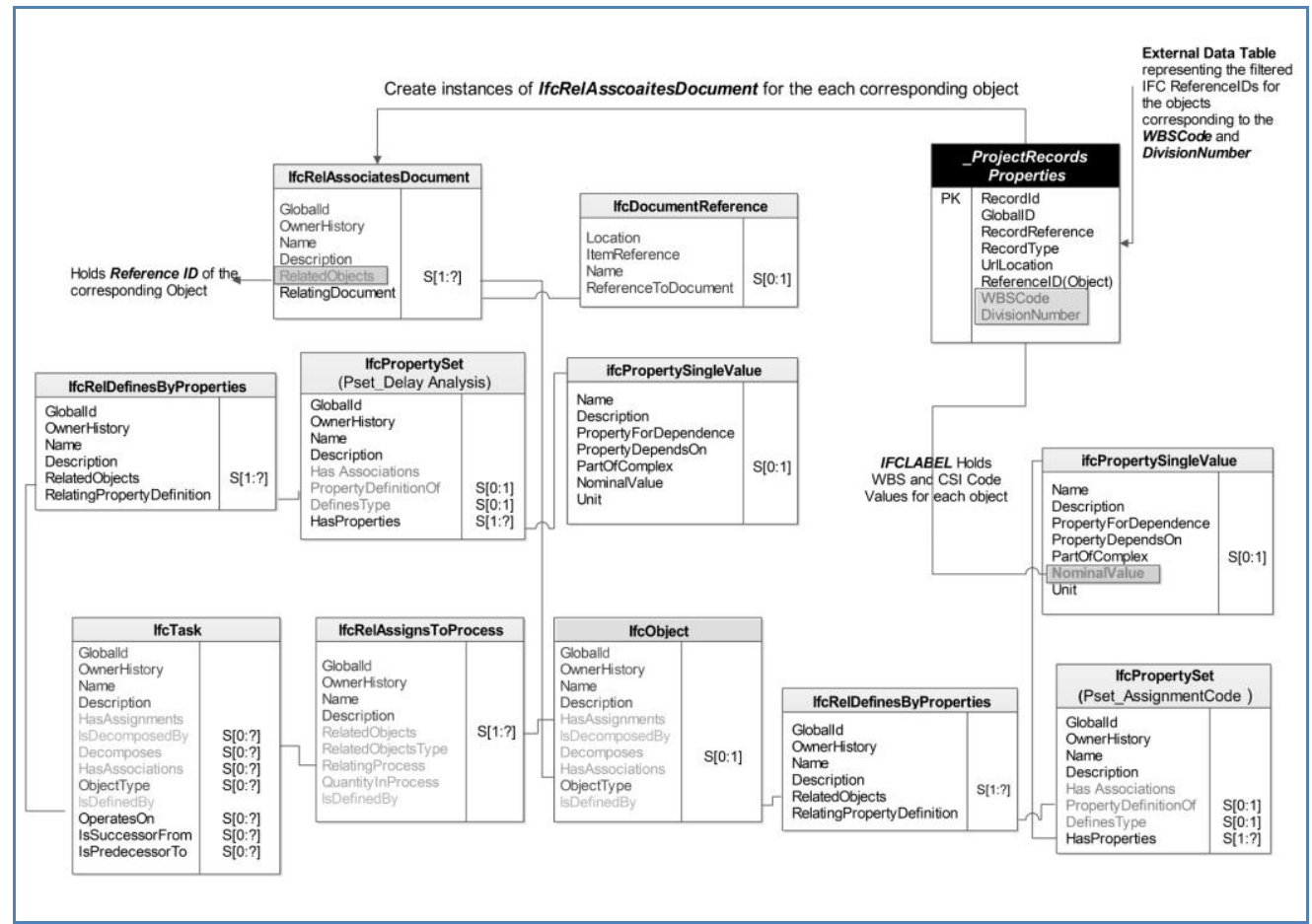

Figure 7 - Proposed connection between partial IFC schema model and_ProjectRecordsProperties

\section{Step 4 - Developing the a document link interface}

In a user entry interface, the user assigns to a mapped IfcDocumentReference table the document reference code (ItemReference), document description(Name), url reference link (Location), associated Work Breakdown Structure code (WBSCode) and associated CSIMaster Division number(CSICode). The associated WBSCode and CSICodes are linked with the objects of the corresponding codes located in the nominal values of IfcPropertySingleValue (Pset_AssignmentCode) creating a repository table _ProjectRecordsProperties that .

An algorithm was utilized to populate instances of the document-object link table ifcRelAssociatesDocument by mapping ItemReference to the RelatingDocument and mapping the Nominal Values WbSCode and CSICode of the IfcPropertySet (Pset_AssignmentCode) to the RelatingObjects. The results are appended to the IFC Step21 files with instances of IfcDocumentReference and IfcRelassociatesDocument representing the project documents and its corresponding object attributes in the BIM model.

\section{Step 5 - User Interface for Claim Analysis}

A user interface using $\mathrm{xBim} \mathrm{C \#}$ is developed that portrays all contemporaneous project documents that are linked with a delay event path within a specified analysis window. Upon selecting a potential delay event_IfcDelayEvent, queries the relevant delay event path of activities_IfcDelayPath and consequently all corresponding contemporaneous project documents ifcDocumentReference previously linked with the BIM objects.

The system when applied showed a significant reduction enabled fast in the retrieval of retrieval of all the related documents related to a delay event. The significant decrease outperforms traditional retrieval of documents through traditional document control systems.

\section{CONCLUSION}

Limited researches are conducted on the application of BIM in the forensic delay the claims process. The financial implications associated with delay claims disputes for claimants are vast. The cost associated in the substantiation of delay claims entail extensive forensic research inter alia the assimilation and evaluation of contemporaneous project records for a given delay event in a limited time period. This evaluation is cost and time-consuming and 
prone to errors and results in failure of the claimant to substantiate its claim as demonstrated in numerous court cases.

This paper investigates the unexplored benefits of incorporating BIM technology in forensic delay claims. The proposed methodology extracts the contemporaneous project documents pertaining to a potential delay event. This is achieved by 1) mapping the contemporaneous project documents with BIM object(s) 2) extending the IFC schema model through creating custom dynamic property sets to the non-proprietary Industry Foundation (IFC) Schema model.

The process has proven to facilitate and enhance the claim process and the Claimant's ability to substantiate their delay claims efficiently and providing better accuracy than the traditional claim process. In addition, it extends the Claimant's ability by performing what-if analysis and exploring the potential outcome of a wider range of potential delay events.

\section{REFERENCES}

1. AACEI Commitee. (2011). "AACE International Recommended Practice No. 29R-03 (FORENSIC SCHEDULE ANALYSIS). " AACE® International

2. Bramble, B. B., and Callahan, M. T. (2010). "Construction Delay Claims, Fourth Edition." Philadelphia: Aspen Publishers Inc., U.S.

3. BuildingSMART. (2018). "IFC Overview summary." <http://www.buildingsmarttech.org/specifications/ifc-overview/> (Jan.18, 2018).

4. Caletka, P. J. (2008). "Delay Analysis in Construction Contracts." Oxford, OX4 2DQ, United Kingdom: Blackwell Publishing Ltd.

5. Carmichael, S., and Murray, M. (2006). "Record keeping for contemporaneous delay analysis: a model for effective event management." Construction Management and Economics, 24, 1007-1018.

6. Carnell, N. J. (2005). "Causation and Delay in Construction Disputes (Second Edition)." Iowa: Blackwell Publishing.

7. $\quad$ Dinga, L., et al. (2017). "An IFC-inspection process model for infrastructure projects: Enabling realtime quality monitoring and control." Automation in Construction, 84, 96-110. doi.org/10.1016/j.autcon.2017.08.029

8. Eastman, C., et al. (2011). "BIM Handbook - A Guide to Building Information Modeling for Owners, Managers, Designers, Engineers, and Contractors - Second Edition." John Wiley \& Sons, Inc.

9. Fawzy, S. A., and El-adaway, I. H. (2013). "Contract Administration Guidelines for Effectively and Efficiently Applying Different Delay Analysis Techniques under World Bank-Funded Projects." J. Leg. Aff. Dispute Resolut Eng. Constr., 4(2), 35-44

10. Fru-Con Construction Corporation v The United States (1999).

11. Gibbs, D.-J., et al. (2013). "An Investigation Into Whether Building Information Modelling (BIM) Can Assist With Construction Delay Claims." Journal of 3-D Information Modeling., 2(1), 45-52.

12. Hamledar, H., et al. (2017). "Automated Schedule and Progress Updating of IFCBased 4D BIMs." Journal of Computing in Civil Engineering, 31(4), 1-16. doi.org/10.1061/(ASCE)CP.1943-5487.0000660

13. Lee, D. G., and Cha, H. S. (2015). "Exploratory Study on BIM-based Information Breakdown Structure for Construction Document Management." KICEM Journal of Construction Engineering and Project Management, 5(1), 32-39. doi:10.6106/JCEPM.2015.5.1.032

14. Lowsley, S., and Linnett, C. (2006). "About Time- Delay Analysis in Construction." RICS Books.

15. Ma, Z., and Lu, N. (2010). "Approach to representing information resources in construction firms by using IFC based on object-oriented method." International Conference on Computing in Civil and Building Engineering., Nottingham University Press: Nottingham, UK, paper 89

16. Motamedi, A., et al. (2016). "Extending IFC to incorporate information of RFID tags attached to building elements." Advanced Engineering Informatics, 30, 39-53. 
17. Park, J., and Cai, H. (2017). "WBS-based dynamic multi-dimensional BIM database for total construction as-built documentation." Automation in Construction, 77, 15-23. https://doi.org/10.1016/j.autcon.2017.01.021

18. Pickavance, K. (2005). Delay and Disruption in Construction Contracts, 3rd Ed., LLP Professional Publishing, London - Singapore.

19. Tanaka, F., et al. (2016). "Bridge Information Model Based on IFC Standards and Web Content Providing System for Supporting an Inspection Process." Proc. of $16^{\text {th }}$ Int. Conf. on Computing in Civil and Building Engineering (ICCCBE 2016). 2016:1140-1147

20. The Foundation Co of Canada Ltd v United Grain Growers Ltd (1995).

21. Vidogah, W., and Ndekugri, I. (1998). "A review of the role of information technology in construction claims management." Computers in Industry, 35(1), 7785. https://doi.org/10.1016/S0166-3615(97)00085-7

22. Wang, R., et al. (2015). "A multidimensional information model for managing construction information." Journal of Industrial and Management Optimization, 11(4), 1285-1300.

23. Wharf Properties Ltd v Eric Cumine Associates (1991).

24. Zhiliang, M., et al. (2011). "Application and Extension of the IFC Standard in Construction Cost Estimating for Tendering in China." Automation in Construction, 20(2), 196-204. https://doi.org/10.1016/j.autcon.2010.09.017

\section{List of Tables}

Table 1 - Potential Delay Events ........................................................................................ 7

Table 2 - Definition of the Delay Claim Property Set …..................................................... 8

Table 3 - Definition of the Pset_AssignmentCode attributes ........................................... 8

Table 4 - Definition of the Pset_Delay Analysis attributes ................................................ 8

Table 5 - Assignment 'Delay Path' Event to the designated activity .................................... 9

List of Figures

Figure 1-Express Specification and Express-G annotation for IfcTask................................ 3

Figure 2 -IFC Schema representation of Time Programme .................................................. 4

Figure 3 -IfcPropertySet for custom dynamic property set ............................................... 4

Figure 4-Comparison between the Traditional and Proposed claim evaluation process ......... 5

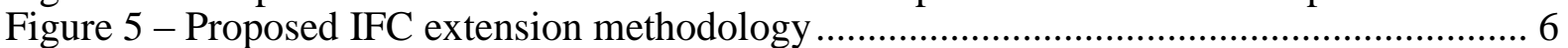

Figure 6 - Pre and post impact of delay event DE03 in analysis window\#1 ........................... 7

Figure 7 - Proposed connection between partial IFC schema model and 